\title{
REVISTA BRASILEIRA DE ENERGIAS RENOVÁVEIS \\ OCUPAÇÃO ATUAL DA TERRA NA BACIA HIDROGRÁFICA DO RIO POXIM NO ESTADO DE SERGIPE USANDO IMAGENS DO GOOGLE EARTH ${ }^{1}$
}

\section{LUCAS DOS SANTOS BATISTA ${ }^{2}$; RAIMUNDO RODRIGUES GOMES FILHO ${ }^{3} \&$ MAIRTON GOMES DA SILVA ${ }^{4}$}

${ }^{1}$ Publicado no Ano de 2019;

2 Mestrando em Recursos Hídricos na Universidade de Sergipe, lucasbaptistaufrb@gmail.com;

${ }^{3}$ Professor Adjunto na Universidade Federal de Sergipe;

${ }^{4}$ Doutorando na Universidade Federal de Recôncavo da Bahia.

RESUMO - As mudanças provocadas pela ação antrópica na paisagem promovem vários impactos sobre o ambiente físico e biológico. $\mathrm{O}$ acompanhamento, a identificação e a orientação para o uso e ocupação racional das terras são de grande importância para o planejamento ambiental. Nesse sentido, o uso de modelo ambiental estruturado em Sistema de Informação Geográfica (SIG) pode contribuir para a construção de dados espaciais que identifiquem a capacidade e as restrições do uso adequado da terra. Diante disso, o objetivo do trabalho foi elaborar o mapeamento da ocupação da terra na bacia hidrográfica do rio Poxim no estado de Sergipe, a partir de imagens de alta resolução espacial adquirida através do Google Earth. Observou-se os seguintes percentuais das classes mapeadas: pastagem $(45,78 \%)$, floresta nativa $(26,33 \%)$, agricultura $(16,73 \%)$, solo exposto (5,66\%), área urbana $(5,34 \%)$ e corpos d'Água (0,13\%). Podendo-se concluir que, a bacia hidrográfica do rio Poxim está inserida em uma área rural, de área relativamente conservada. Os resultados obtidos mostram a utilidade da espacialização de uso e cobertura das terras, utilizando SIG como ferramenta complementar e eficiente para fornecer análise espacial dos diversos usos das terras.

Palavras-Chave - Sistema de Informação Geográfica (SIG), Planejamento, Ocupação racional. 


\title{
CURRENT OCCUPATION OF THE LAND IN THE CATCHMENT AREA OF THE RIVER IN THE STATE OF SERGIPE POXIM USING IMAGES FROM GOOGLE EARTH
}

\begin{abstract}
The changes caused by anthropic action in the landscape promotes several impacts on the physical and biological environment. The monitoring, identification and orientation for the rational use and occupation of the land are of great importance for the environmental planning. In this sense, the use of environmental model structured in Geographic Information System (GIS) can contribute to the construction of spatial data to identify the capacity and the restrictions on the appropriate use of the land. In addition, the objective of this work was to elaborate the mapping of the occupation of land in Cebu river basin in the state of Sergipe, from images of high spatial resolution gained through Google Earth. We observed the following percentages of the mapped classes: pasture (45.78\%), native forest $(26.33 \%)$, agriculture (16.73\%), exposed soil (5.66\%), urban area $(5.34 \%)$ and water bodies $(0.13 \%)$. It may be concluded that the Cebu river basin is inserted in a rural area, relatively preserved area. The results obtained show the usefulness of the spatialization of use and coverage of land, using GIS as a complementary tool and efficient to provide spatial analysis of various uses of the land.
\end{abstract}

Keywords - Geographic Information System (GIS), Planning, rational occupation. 


\section{Introdução}

O uso e a cobertura da terra têm se tornado um tema muito discutido nos diversos níveis do conhecimento, devido às diversas problemáticas que o uso e ocupação desordenados trouxeram ao meio ambiente. Ações desenfreadas a exemplo dos desmatamentos para implantação de agroindústrias, de mineradoras, para a criação de animais, plantações e muitas outras atividades ligadas ao uso e cobertura da terra, se constituem hoje como um dos grandes desafios para as políticas de controle ambiental (ARAÚJO; LOBÃO, 2009).

O uso, ocupação e cobertura da terra podem ser sintetizados através de mapas sendo a informação mais acessível em uma imagem de satélite, pois a mesma permite a visualização e identificação direta dos elementos ali geometricamente apresentados. Mapas indicam a distribuição espacial da tipologia da ação antrópica que pode ser identificada pelos seus padrões homogêneos característicos na superfície terrestre através de análise em imagens remotamente sensoriadas. Sua identificação, quando atualizada, é de considerável relevância ao planejamento e orienta à ocupação da paisagem, respeitando sua capacidade de suporte e/ou sua estabilidade/vulnerabilidade (LEITE; ROSA, 2012).

A avaliação da dinâmica do uso e cobertura da terra é de relevante importância, pois medida em que os efeitos do seu uso desordenado causam deterioração no ambiente. Os processos de desmatamento e erosão intensos e os assoreamentos e inundações desenfreados de reservatórios e cursos d'água são consequências do mau uso e ocupação da terra. Assim, verifica-se que o levantamento do uso da terra, em uma determinada região, torna-se um aspecto fundamental para a compreensão dos padrões de organização do espaço e planejamento de políticas públicas. Entretanto, as medidas para o planejamento do uso da terra têm sido, até recentemente, baseadas em informações fragmentadas e desatualizadas sobre os efeitos do uso do solo no ambiente (PRADO et al., 2007).

Em uma bacia hidrográfica o uso e cobertura da terra são fatores determinantes na degradação ambiental das águas, pois é a partir deles que serão definidos os usos 
prioritários da bacia (ESPINDULA, 2012). Visto que algumas práticas de usos da terra podem contribuir para a degradação dos ecossistemas. Estas práticas estão associadas principalmente à demanda por produção e à urbanização de áreas sem infraestrutura básica, como o recolhimento e tratamento de resíduos sólidos e líquidos, energia, entre outros. Quando essas atividades são desenvolvidas próximas a ecossistemas aquáticos, podem ter efeito negativo direto na qualidade da água e assim, causar crises na oferta e demanda hídrica (TUNDISI, 2008).

Assim, considerando a importância de se obter maiores informações sobre as práticas de uso da terra, no presente trabalho objetivou-se: Classificar a ocupação da terra, na bacia hidrográfica do rio Poxim, no estado de Sergipe, com o emprego de ferramentas SIG.

\section{Matérias e Métodos}

O trabalho foi realizado na bacia hidrográfica do rio Poxim, que compreende uma área de $346,72 \mathrm{~km}^{2}$ (Figura 1), localizada na porção leste do estado de Sergipe, abrangendo parte dos municípios de Itaporanga d'Ajuda, Areia Branca, Laranjeiras, Nossa Senhora do Socorro, São Cristóvão e Aracaju. Situada entre as coordenadas geográficas de $10^{\circ} 55^{\prime}$ e $10^{\circ} 45^{\prime}$ de latitude Sul e $37^{\circ} 05^{\prime}$ e $37^{\circ} 22^{\prime}$ de longitude Oeste (FERREIRA et al., 2011).

De acordo a classificação de Köppen que é baseada no pressuposto, da origem na fitossociologia e na ecologia, de que a vegetação natural de cada grande região da Terra é essencialmente uma expressão do clima nela prevalecente. Diante disso a área da bacia é caracterizada pelo clima do tipo A's Tropical (chuvoso com verão seco), com índice pluviométrico médio anual equivalente a $1.200 \mathrm{~mm}$, período de chuvas concentrado nos meses de março a julho, e temperatura entre $23{ }^{\circ} \mathrm{C}$ nos meses mais frios (julho e agosto) e $31{ }^{\circ} \mathrm{C}$ nos meses mais quentes (dezembro e janeiro) (SILVA, 2001). 


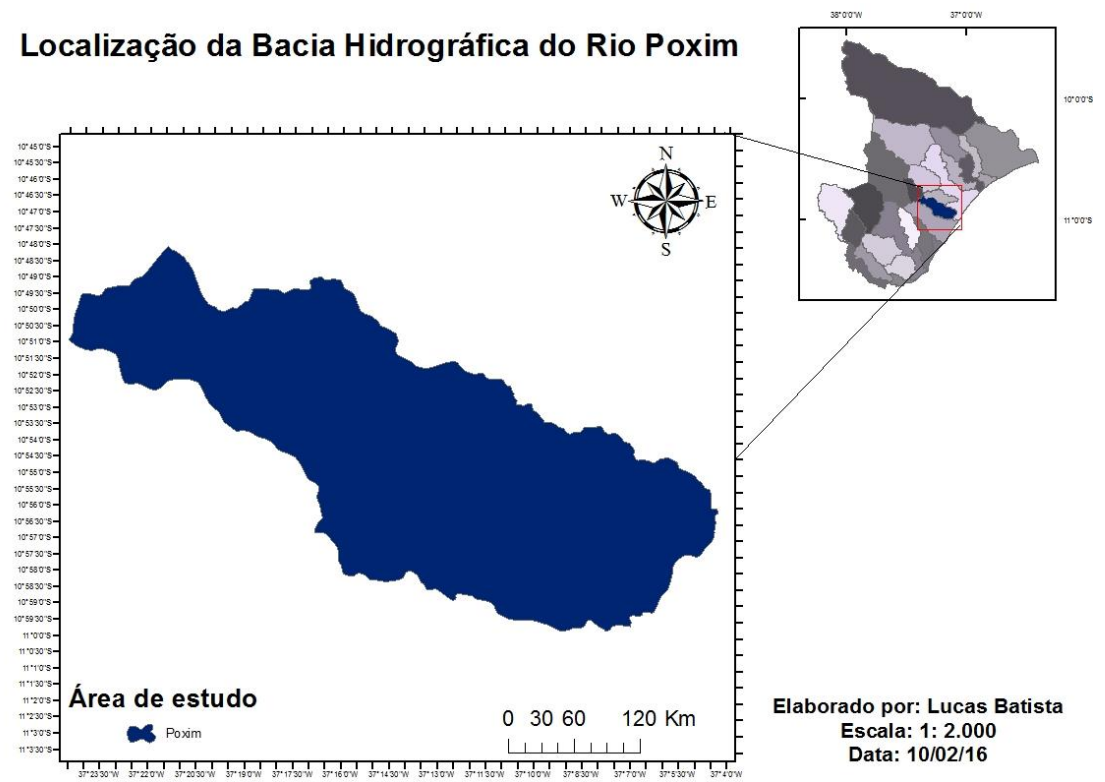

Figura 1 - Localização da bacia hidrográfica do rio Poxim

$\mathrm{Na}$ caracterização da área o procedimento técnico metodológico teve como princípio a nova abordagem de mapeamento elaborada por Moreira et al., (2011), (Figura 2), que usa como base as imagens de alta resolução espacial capturadas do Google Earth e técnica de interpretação visual descrita por (NOVO, 2008). A aquisição das imagens do Satélite GeoEye da bacia foi realizada através do software Google Earth 7.1. Para recobrir o limite da bacia hidrográfica, necessitou-se de um conjunto de seis cenas, as mesmas salvas no formato (JPEG). Os parâmetros de georreferenciamento foram inseridos nas imagens, em seguida gerou-se um mosaico das cenas convertidas e registradas no sistema de coordenadas Universal Transversa de Mercator (UTM), fuso 24 L e Datum WGS84 e sua exportação no formato GeoTIFF.

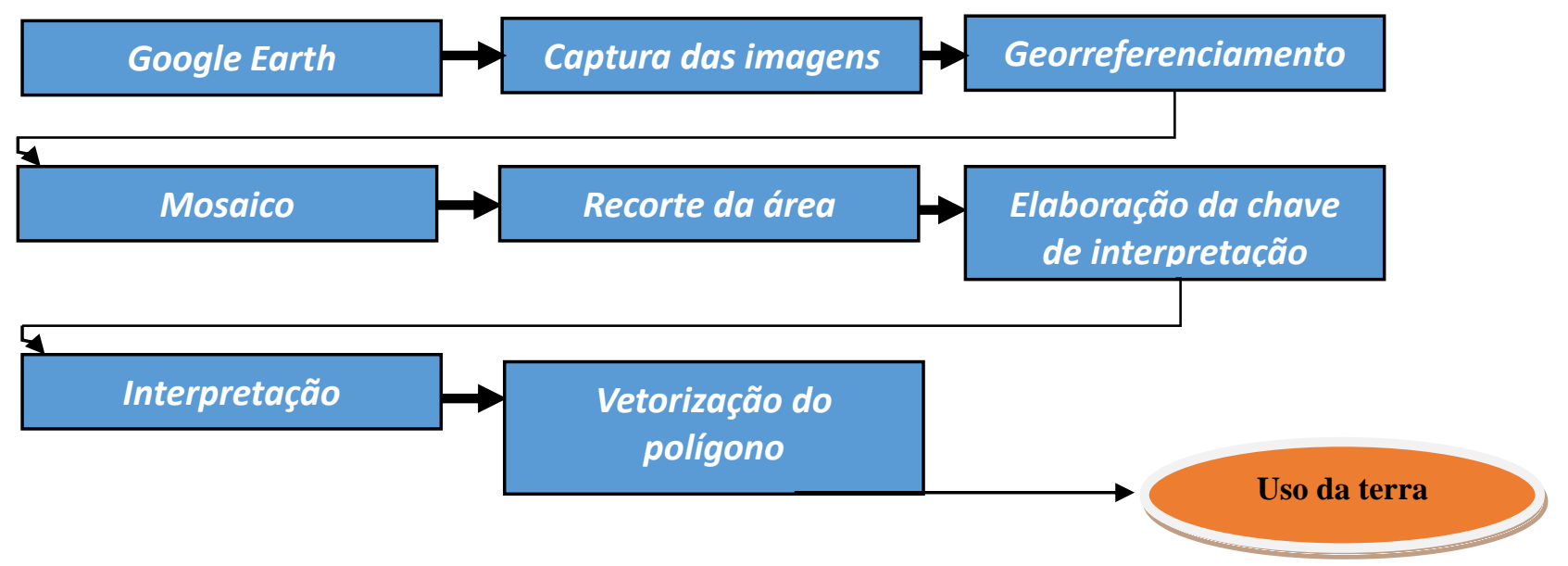

Figura 2. Fluxograma das operações realizadas no aplicativo do sistema de informações geográficas para criar o mapa de uso da terra 
Por meio do reconhecimento da área de estudo por meio das imagens de alta resolução, a acervos diversos e excursões de campo foram identificadas seis classes de ocupação e cobertura das terras na bacia hidrográfica do rio Poxim, sendo elas: vegetação nativa, corpos d'água, agricultura, solo exposto, pastagem e área urbana. A análise visual é definida como ato de examinar uma imagem com o propósito de identificar objetos e estabelecer julgamentos sobre suas propriedades. Durante o processo de interpretação, as seguintes atividades são realizadas quase simultaneamente: detecção, reconhecimento, análise, dedução, classificação e avaliação da precisão. Além disso, a interpretação visual se baseou em sete características da imagem no processo de extração de informações, tais elementos como: tonalidade/cor, textura, padrão, localização, forma, sombra e tamanho (NOVO, 2008). Aliado ao suporte metodológico a orientação do Manual Técnico de Uso das Terras do IBGE (2006).

\section{Resultados e Discussão}

Considerando a metodologia utilizada foi possível a identificação e classificação das seguintes classes de ocupação e cobertura das terras da bacia hidrográfica do rio Poxim, conforme a Figura 3 e Tabela 1.

Mapa de Uso da Terra e Cobertura Vegetal da Bacia do Rio Poxim

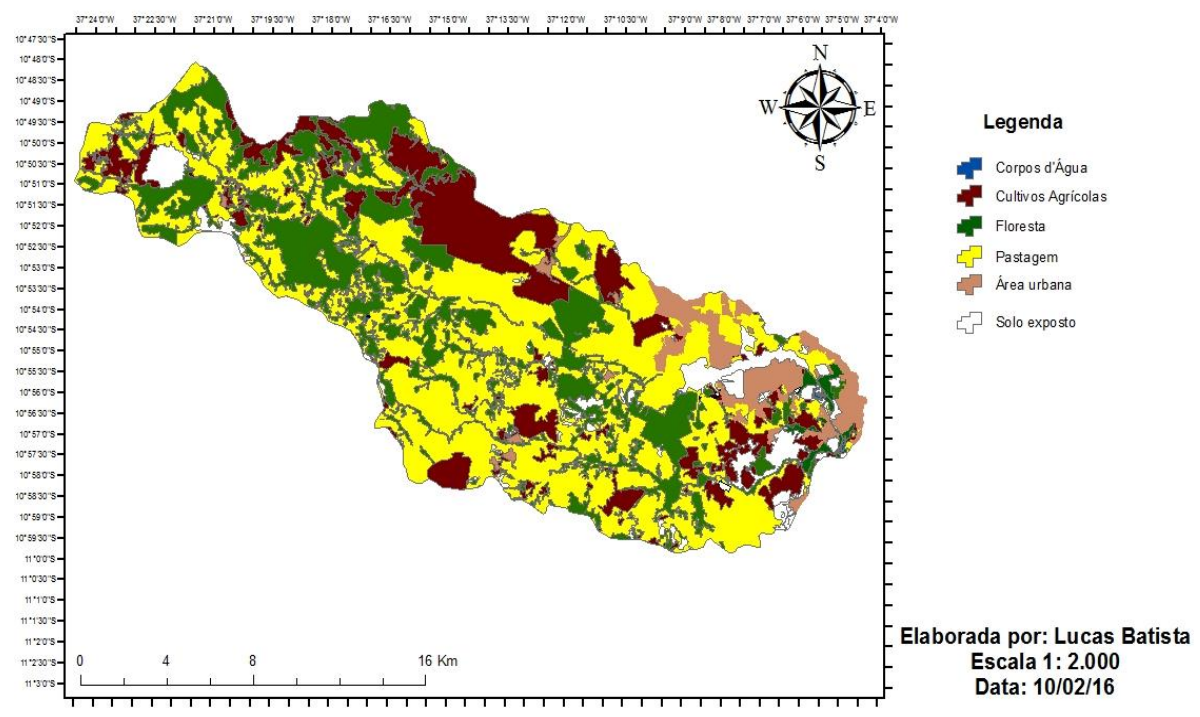

Figura 3. Mapa de uso da terra e cobertura vegetal da bacia do rio Poxim 
Tabela 1 - Classificação percentual e ocupacional da bacia

\begin{tabular}{ccc} 
Classe de uso da terra & Área $\left(\mathbf{k m}^{\mathbf{2}}\right)$ & Percentagem $(\boldsymbol{\%})$ \\
Corpos d'água & 0,47 & 0,13 \\
Área urbana & 18,63 & 5,34 \\
Solo exposto & 19,73 & 5,66 \\
Cultivos agrícolas & 58,36 & 16,73 \\
Floresta & 91,32 & 26,33 \\
Pastagem & 15,96 & 45,78 \\
\hline
\end{tabular}

Em conformidade com os resultados, observa-se que a pastagem é a classe com maior expressividade na área da bacia, com aproximadamente $46 \%$ de abrangência. Composta em sua maioria pela espécie Brachiaria decumbens que possui baixa exigência em fertilidade do solo, não tolera solos argilosos e secas prolongadas, características presentes na área. Segundo Souza et al. (2008), em áreas de pastagens manejadas de forma ineficiente, normalmente sem rotação e com excesso de animais, é comum a presença de camadas compactadas pelo pisoteio dos animais. Em solo compactado, ocorrem menor infiltração da água de chuvas e, assim, maior escoamento superficial, intensificado pelo aumento na declividade e presença de pouca matéria vegetal na superfície do solo (ROSOLEM et al., 1994). Assim, provavelmente causando o assoreamento nos corpos d'águas da bacia, já que a classe da pastagem abrange quase metade da área total da bacia.

Já a floresta nativa consiste em 26,33\% que compreende uma área de 91,32 $\mathrm{km}^{2}$ da área total da bacia, Cardoso e Aquino (2014), ao estudarem o uso e cobertura das terras da sub-bacia do Riacho do Roncador em Timon no Maranhão, observaram que a classe de vegetação nativa contribuía com $70 \%$ da área da sub-bacia.

A floreta nativa se constitui, de grande importância na qualidade e quantidade dos corpos d'água, já que as florestas tropicas possuem a capacidade de conservar mineras essências devido à alta taxa de decomposição e fluxo de água. Segundo Davide et al. (2000), as matas conseguem reter cerca de $80 \%$ do fósforo e $89 \%$ do nitrogênio proveniente do escoamento superficial das áreas adjacentes, dependendo do desenvolvimento e tipo da vegetação como também do tipo de solo e relevo entre outros fatores.

Revista Brasileira de Energias Renováveis, v.8, n.1, p. 01- 11, 2019 
A agricultura representa $16,73 \%$ da área total da bacia. Essa classe é definida segundo Cardoso e Aquino (2014), como áreas destinadas a plantio agrícola, seja temporário, permanente, seja de subsistência ou intensivo (comercial). E de terra preparada ou em manejo para tal fim, incluindo aquelas em "pousio" resultante de cultura recém-colhida, mesmo que eventualmente apresente-se em solo descoberto. Esse tipo de agricultura exploradora tem contribuído com a intensificação da degradação ambiental dessa área, é notório o aumento dessa prática na bacia.

O solo exposto é definido pela ausência de cobertura vegetal e elevada radiação eletromagnética e exerce uma área de 5,66\% da bacia, decorrente da exploração de empresas de extração de terra. Valor menor do que Carvalho et al. (2015) encontrou ao estudar a bacia hidrográfica do rio Jacaré, o solo exposto correspondeu 21,8\% da área total. De acordo com Fastino et al. (2014) o solo exposto constitui um cenário alarmante, já que o desmatamento é o fator que contribuiu decisivamente para a exposição dos solos aos agentes erosivos.

A classe urbana corresponde a uma porcentagem de 5,34\%, que engloba uma área de 18,63 $\mathrm{km}^{2}$ em toda a bacia. Para Silva et al., (2016), a classe de área urbana correspondeu a aproximadamente $3 \%$ da área da bacia hidrográfica do rio Uma, o que indica que os impactos provenientes das atividades humanas desenvolvidas em centros urbanos são relativamente baixos, uma vez que, a população urbana do município é pequena.

\section{Conclusões}

O uso das ferramentas básicas do geoprocessamento mostrou-se capaz para esse tipo de trabalho, gerando conhecimento importante em formato de mapas e tabelas, fundamental para a compreensão de estudo da área.

Para a ocupação e cobertura das terras, deve-se haver um planejamento minucioso para que não haja degradação, ou seja, grandes impactos ambientais.

A bacia hidrográfica do rio Poxim pode ser considerada inserida em uma esfera rural. 


\section{Referências Bibliográficas}

ARAUJO, A. M.; LOBÃO, J. S. B. Análise do uso e cobertura da terra na Carta Santa luz SC-24-Y-D-III a partir das geotecnologias. in Anais do XIV Simpósio Brasileiro de Sensoriamento Remoto, Natal, Abr. 2009, pp .3455-3462, 2009.

CARDOSO, J.; AQUINO, C. M. S. Mapeamento atual do uso e cobertura das terras da sub-bacia do Riacho do Roncador em Timon (MA) utilizando imagens do Google Earth. OKARA: Geografia em debate, 8, (2), pp. 328-343, 2014.

CARVALHO, T. B.; SANTOS, R. B; PEIXOTO, J. S. Uso e ocupação do solo na bacia hidrográfica do rio Jacaré, Sergipe. In Anais do $2^{\circ}$ Congresso Internacional do Rede de Saneamento e Abastecimento de Água, Aracaju, pp. 1-8, 2005.

DAVIDE, A. C.; REBOUÇAS, A. C. Aguas doces no Brasil- capital Ecológico, uso e conservação, Ed. Escrituras, 2000.

ESPINDULA, N. L. Influência do uso e cobertura da terra na qualidade da água na bacia hidrográfica do rio bubu, município de Cariacica - ES. 69 p. Trabalho de Conclusão de Curso (Graduação em Geografia) Universidade Federal do Espírito Santo, Vitoria, 2012.

FASTINO, A. B.; RAMOS, F. F.; SILVA, S. M. P. Dinâmica temporal do uso e cobertura do solo na bacia hidrográfica do rio Doce $(\mathrm{RN})$ com base em sensoriamento remoto e SIG: uma contribuição aos estudos ambientais". Sociedade e Território, Natal, 26, (2), pp. 18 - 30, 2014.

FERREIRA, A.; AGUIAR NETTO, A.O.; SANTOS, T.I.S.; SANTOS, B. L.; MATOS, E.L. Nascentes da sub-bacia hidrográfica do rio Poxim, estado de Sergipe: da degradação à restauração. Revista Árvore, 35, (2), pp. 265-277, 2011.

IBGE, Instituto Brasileiro de Geografia e Estatística. Manual Técnico de Uso da Terra. Rio de Janeiro, 2006. 
LEITE, E. F.; ROSA, R. Análise do uso, ocupação e cobertura da terra na bacia hidrográfica do rio Formiga, Tocantins. Revista Eletrônica de Geografia, 4, (12), pp. 90-106, 2012.

MOREIRA, A. M.; ADAMI, M.; RUDORFF, B. F. T.; BERNARDES, T. Uso de imagens do Google Earth capturadas através do software Stich map e do TM/Landsta-5 para mapeamento de lavouras cafeeiras - nova abordagem metodológico. in Anais do XV Simpósio Brasileira de Sensoriamento Remoto, Curitiba, Abr. 2011, pp. 481-488, 2011.

NOVO, E. M. L. M. Sensoriamento Remoto: Princípios e aplicações. Ed. Edgard

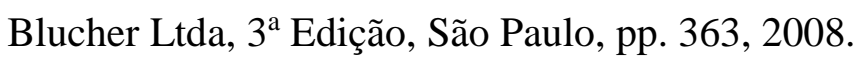

PRADO, R. B; NOVO, E. M. L. M; PEREIRA, M. N. Avaliação da dinâmica do uso e cobertura da terra na bacia hidrográfica de contribuição para o reservatório de Barra Bonita - SP. Revista Brasileira de Cartografia, 1, (20), pp.127-135, 2007.

ROSOLEM, C. A.; VALE, L. S. R.; GRASSI FILHO, H.; MORAES, M. H. Sistema radicular e nutrição do milho em função da calagem e da compactação do solo. Revista Brasileira de Ciência do Solo, v.18, pp. 491-497, 1994.

SILVA, D. C. C.; SALES, J. C. A.; ALBUQUERQUE FILHO, J. L.; LOURENÇO, R. W. Características morfométricas e suas implicações no acúmulo de sedimentos em reservatórios: o caso da represa Hedberg, Iperó/SP. RA'E GA, v. 36, p. 225-247, 2016.

SILVA, Z. F. B. Cenária atual da seç̧ão urbana do Rio Poxim. 85 p. Trabalho de Conclusão de Curso. (Especialização em Gestão de Recursos Hídricos em Meio Ambiente) - Universidade Federal de Sergipe, Aracaju, 2001.

SOUZA, G.S. de; LIMA, J.S. de S.; SILVA, S. de A.; OLIVEIRA, R.B. de. Variabilidade espacial de atributos químicos em um Argissolo sob pastagem. Acta Scientiarum. Agronomy, v.30, pp.589-596, 2008. 
TUNDISI, J. G. Recursos hídricos no futuro: problemas e soluções. Estudos Avançados, v. 22, n. 63, pp. 7-16, 2008. 